\title{
PERFORMANCE OF RC FRAME STRUCTURE WITH VARIOUS BEAM TO COLUMN FLEXURAL CAPACITY RATIO - A CASE STUDY
}

\author{
Sudip Karanjit \\ Department of Civil Engineering, Khwopa Engineering College, Libali-8, Bhaktapur, Nepal
}

\begin{abstract}
The effectiveness of various Strong Column Weak Beam (SCWB) factors to enhance seismic performance is assessed for Reinforced Concrete (RC) frame building structures. In this study five RC frame buildings of different storey numbers have been analysed using different column overdesign factors. The results are compared as the influence of various SCWB factor over the expected performance of selected RC frame buildings in terms of enhancement in capacity and failure mechanism. With the lower value of SCWB factor insignificant change in capacity curve is observed while gradual improvement is observed with the higher factors. In terms of failure mechanism gradual change from column failure mechanism to beam failure is observed but the hinge formation at the base of bottom storey column is seen even with the higher value of SCWB factor. The effectiveness of alternative method of column flexural capacity enhancement by proposed modified SCWB (MSCWB) was also studied. MSCWB is found to be more effective in terms of enhancement in capacity curve and failure mechanism.
\end{abstract}

Keywords: SCWB, RCC structure, pushover analysis, failure mechanism

\section{Introduction}

SCWB is basically the column over-design concept in which the ratio of sum of plastic moment capacity of column to the sum of those in beam is kept greater by some factor in each joint (Fig 1). The concept has long been accepted as a key concept for the prevention of column failure mechanism. The reason behind is the fact that in the column failure mechanism, failure concentration occurs at single storey (Fig 2 (b)) leading to the catastrophic collapse of whole structure, whereas in beam failure mechanism (Fig 2 (a)) failure occurs in beams which gives better stability and energy dissipation system than the storey failure mechanism. It is observed during past earthquake (including Gorkha earthquake 2015) that most destructive collapse of the frame structure is due to the column failure (storey failure) mechanism. Realizing this fact various national and international building codes have adopted certain column overdesign factor in

\footnotetext{
*Corresponding author: Sudip Karanjit

Department of Civil Engineering, Khwopa Engineering

College, Libali-8, Bhaktapur, Nepal

Email: sudipkaranjit@gmail.com

(Received: 2016 Nov 10 Accepted: 2016 Nov 29)
}

comparison to beam in order to ensure that the hinging in the beam occurs first than the column. ANSI/AISC 341-05 recommends the minimum SCWB factor of 1.0, ACI 318-05 recommends value of 1.2, Euro code EN 1998-01 (EC-08) recommends for the value of 1.3, while some other code like NBC105:1994 and IS1893:2002 are not yet having such provisions.

Although numerous researches were performed for the determination of optimum beam to column over strength factor and the significance of the SCWB provision, it is difficult to draw deterministic conclusion from them. The study of Se-Woon Choi and Hyo-Seon Park (2009) on evaluation of the minimum column to beam strength ratios for special steel moment frame indicated the requirement of more column-tobeam moment strength ratio than that specified in ANSI/AISC 341-05 (SCWB $\geq 1.0$ ). Study presented the optimum seismic design algorithm for preventing plastic hinges on the column parts of joints in special steel moment frames. The research performed by Richard et al. (2009) on the seismic performance of reinforced concrete 
intermediate moment frames (IMF) in moderate seismic zone using ACI design provisions also concluded that the addition of a low value of SCWB ratio 1.2 as advised by ACI design provision did not offer significant improvement over performance of IMF frame.

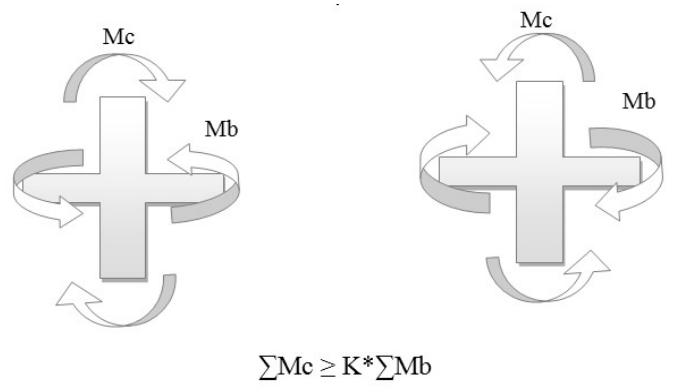

Fig $1 \mathrm{SCWB}$ provision (SCWB)

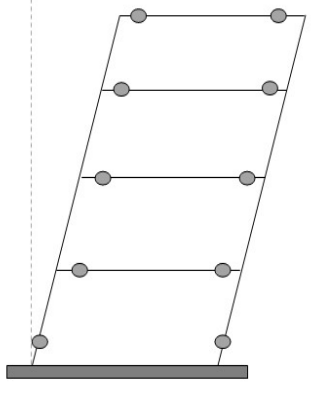

Fig 2 (a)

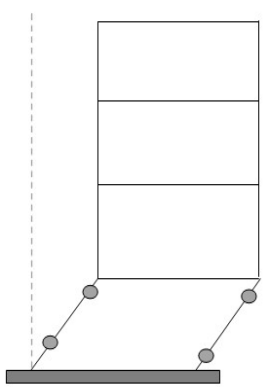

Fig 2 (b)
Fig 2 Failure mechanism of RC frame structure (a) Beam failure mechanism (b) Column failure mechanism

Tetsuro et al. (2000) performed the probabilistic evaluation of column overdesign factors for RC frames. The probabilistic evaluation for the target values of SCWB factor was carried out for the limited occurrence probability of unpreferable failure modes. A stochastic limit analysis procedure was carried out using the linear programming method and the first-order reliability method and the likely failure modes of weak beam strong column designed structures were investigated using this procedure. The result indicated much higher value of SCWB factor requirement with uncertain loads and member strengths than in deterministic cases.

Sharfuddin et al. (2010) performed study on probabilistic evaluation of column over-design factor for frame structures considering seismic base shear distribution of Bangladesh National Building Code. Based on the investigations, the target SCWB values were proposed that ensures probabilistically the preferable entire beam hinging failure mode and avoid probabilistically the undesirable storey collapse modes of the frame. It was concluded that with the same reliability level the target SCWB factor increases with increase in number of storey.

The partial capacity design evaluation presented by Muljati and Lumantarna (2008) on Indonesian Concrete Building Code concluded that the formulation of column magnification factor needs further observation, and the column overstrength factor applied in the Indonesian Concrete Building Code is not conservative to meet the SCWB requirement. In the study, interior columns are allowed to be plastic while keeping the perimeter column elastic.

The experimental investigation carried out in beam-column specimen incorporating slab have shown the significant contribution of slab in beam flexural capacity (Eshani and Wight, 1985; Leon and Jira, 1986) thus reducing the column to beam flexural capacity ratio. The paper presented by Eshani and Wight (1985) recommends for the consideration of slab reinforcement equal to the width of the beam on each side while calculating the flexural capacity of beam. Also the report of ACI ASCE Committee 352 (1985) on beam column joints in monolithic RC structure recommends SCWB factor of 1.4 instead of 1.2 given by ACI 318-05 (if strength contribution of slab to beam is excluded). Yuan and $\mathrm{Hu}$ (2009) also performed the study to find out the influence of steel bars in monolithic floor slabs on the yielding-damage mechanism of frame structures. The research indicated that slab bars in the tensile zone have a direct enhancing action on the capacity of the beam resisting negative moment. The design method neglecting the slab bars will underestimate the actual flexural strength of the frame beam, which result the seismic behavior of the structure from strong column weak beam to strong beam weak column.

For the present study five RC buildings between 3 to 8 storey and various aspect ratios have been 
selected to best represent the present RC building being practiced in Nepal. The selected models were designed as per current provision of IS code to fulfill requirement of Special Moment Resisting Frame (SMRF) With the help of macro based spreadsheet program building models were checked for the SCWB factor at the beam column joints and various SCWB factors were applied to the models. Performance of all the models was accessed with the help of non linear static analysis in term of their failure mechanism and their performance curve. Performance of building models was also checked with the application of proposed MSCWB.

\section{RC Frame Selection and Design}

$\mathrm{RC}$ frame structures were selected to best represent the most of the RC frame buildings being built in context of Nepal with various storey height and aspect ratio in plan.

\subsection{Building Selection}

Typical 3, 5 and 8-storey RCC frame building structures with the detail given below were selected for the study (Table 1).

\subsection{Analysis and Design of Selected Models}

Interactive finite element analysis program SAP2000 v14.0.0. has been used for the modelling analysis and design of structure. Analysis and design of RC frame structures were carried out to fulfil the requirement of code IS456:2000; IS1893:2002; IS13920:1993 with the section and material properties given below (Table 2 and 3).

\subsection{Application of Various Column Over Design Factor}

Model RC frame had been checked for various SCWB factors (1.0, 1.2, 1.5 and 2.0) and moment capacity was increased for the column not satisfying the SCWB factor. Macro based spreadsheet program had been generated to check the data obtained from FEM analysis program and to apply suitable reinforcement to fulfil required SCWB factors.

Table 1 Descriptions of buildings

\begin{tabular}{|l|c|c|c|c|c|}
\hline Model & 1 & 2 & 3 & 4 & 5 \\
\hline Plinth Area $\left(\mathrm{m}^{2}\right)$ & 39.2 & 82.8 & 39.2 & 80.8 & 282.4 \\
\hline No. of Storey & $\begin{array}{c}3+\text { Stair } \\
\text { Cover }\end{array}$ & $\begin{array}{c}3+\text { Stair } \\
\text { Cover }\end{array}$ & $\begin{array}{c}5+\text { Stair } \\
\text { Cover }\end{array}$ & $\begin{array}{c}5+\text { Stair } \\
\text { Cover }\end{array}$ & $\begin{array}{c}\text { 8 + Stair } \\
\text { Cover }\end{array}$ \\
\hline Plan Aspect Ratio & $1: 2.5$ & $1: 1.35$ & $1: 2.5$ & $1: 1$ & $1: 1.9$ \\
\hline Storey Height $(\mathrm{m})$ & 2.75 & 2.75 & 2.75 & 2.75 & 3.00 \\
\hline
\end{tabular}

Table 2 Basic sectional dimension of the $\mathrm{RC}$ members

\begin{tabular}{|l|c|c|c|c|c|}
\hline Model & 1 & 2 & 3 & 4 & 5 \\
\hline Beam $(\mathrm{mm} \times \mathrm{mm})$ & $230 \times 350$ & $230 \times 350$ & $230 \times 350$ & $230 \times 350$ & $300 \times 400$ \\
\hline Column $(\mathrm{mm} \times \mathrm{mm})$ & $300 \times 300$ & $300 \times 300$ & $300 \times 300$ & $300 \times 300$ & $450 \times 450$ \\
\hline
\end{tabular}

Table 3 Material properties

3a) Concrete properties

\begin{tabular}{|l|l|}
\hline Modulas of Elasticity E $\left(\mathrm{N} / \mathrm{mm}^{2}\right)$ & 22360 \\
\hline Unit Weight $\gamma\left(\mathrm{KN} / \mathrm{m}^{3}\right)$ & 25 \\
\hline Poisson's ratio $v$ & 0.15 \\
\hline Characteristic Strength Fck $\left(\mathrm{N} / \mathrm{mm}^{2}\right)$ & 20 \\
\hline
\end{tabular}

3b) Reinforcement properties

\begin{tabular}{|l|l|}
\hline Modulas of Elasticity E $\left(\mathrm{N} / \mathrm{mm}^{2}\right)$ & $2 \times 10^{5}$ \\
\hline Unit Weight $\gamma\left(\mathrm{KN} / \mathrm{m}^{3}\right)$ & 76.97 \\
\hline Poisson's ratio $v$ & 0.3 \\
\hline Yield strength fy $\left(\mathrm{N} / \mathrm{mm}^{2}\right)$ & 415 \\
\hline
\end{tabular}




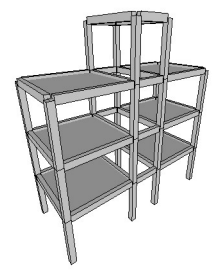

Model 1

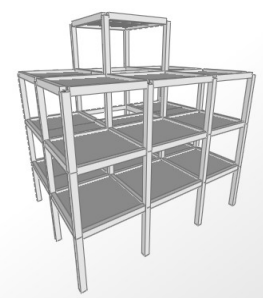

Model 2

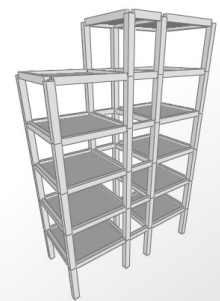

Model 3

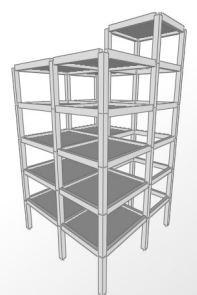

Model 4

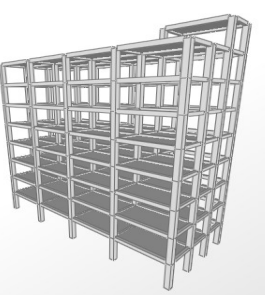

Model 5

Fig 3 FEM model of selected building

As the current SCWB provision does not apply any column over design factor at the base of the bottom storey column (current SCWB has no any provision to prevent column hinging at base of bottom storey column), above structures were also checked with the application of column overdesign factor at the base of the bottom storey column which is termed as MSCWB in this research document. In MSCWB (in-addition to SCWB) column overdesign factors were applied also at the base of bottom story column to enhance the originally designed moment capacity of column by some factor (MSCWB 1.0, 1.2, 1.5 and 2.0). Spreadsheet program had been used to determine section and reinforcement requirement which was applied to FEM analysis program to fulfil required MSCWB factors.

\section{Performance Evaluation}

To achieve the main objectives of the study, nonlinear static analysis has been carried out in SAP2000 v14.0.0. Various parameters used for analysis is explained below.

Performance Evaluation/ Failure Mechanism: The seismic performance of the buildings, were evaluated with the help of pushover curve (Base shear versus Roof displacement) and response spectrum curve (Acceleration versus Time Period) overlayed in acceleration displacement response spectrum (ADRS) format after converting their domain to spectral acceleration and spectral displacement as per ATC40 guideline. The intersection of these capacity and demand curve gives the performance point, which is analysed for the further evaluation process. Terms and parameters used for performance evaluation are explained below.
Table 4 Parameter for ADRS curve

\begin{tabular}{|c|c|c|}
\hline \multirow{2}{*}{ Parameter } & \multicolumn{2}{|c|}{ Adopted demand } \\
\cline { 2 - 3 } & Design EQ & Maximum EQ \\
\hline $\mathrm{Ca}$ & 0.18 & 0.36 \\
\hline $\mathrm{Cv}$ & 0.3 & 0.6 \\
\hline
\end{tabular}

Ca: Effective peak acceleration of the ground, $\mathrm{Cv}$ : 5 percent-damped response of a 1 second system, $\mathrm{V}$ : Base shear at performance point, D: Roof displacement at performance point, Sa: Spectral acceleration at performance point and Sd: Spectral displacement at performance point

Hinge Unloading Method: Hinge unloading method tested can be listed as: (i) Unload entire structure, (ii) Apply local redistribution and (iii) Restart using secant stiffness. The pushover curves for the three methods were found similar before reaching abrupt strength degradation point. First two methods fail to give the solution after abrupt strength degradation, for the same reason restart using secant stiffness had been adopted for the hinge unloading method in present case.

Hinge Type: For Column default FEMA 356 concrete column flexure P-M-M with lateral confirming reinforcement and for Beam default FEMA 356 concrete beam flexure M3 with lateral confirming reinforcement has been adopted.

Load Pattern: Acceleration in specified direction $\mathrm{X} / \mathrm{Y}$ had been applied as pushover load.

Hinge Length: $10 \%$ of relative length of line has been adopted as effective hinge length. 


\section{Result and Discussion}

Result from detail pushover analysis and failure mechanism observation can be summarised as:

a) As the structures were well designed as per the design requirement of IS codal provisions performance of the structures were found satisfactory with demand requirement set as per IS1893:2002 (Fig 4 (a) to Fig 4 (b)).

b) With the application of SCWB factor, gradual enhancement in ADRS curve was seen. With lower SCWB factor of 1.2 only minor enhancement in ADRS curve has been observed for all building models where as factor of 1.5 shows the improvement in deflection capability only. SCWB factor 2.0 shows the considerable enhancement in both base shear and deflection capability (Fig 4 (a) to Fig 4 (d)). In terms of failure mechanism also, there was only minor improvement observed with the lower SCWB factor of 1.2 and 1.5, where as with the factor of 2.0 considerable improvement has been observed (Fig 5 (a) to Fig 5 (d)).

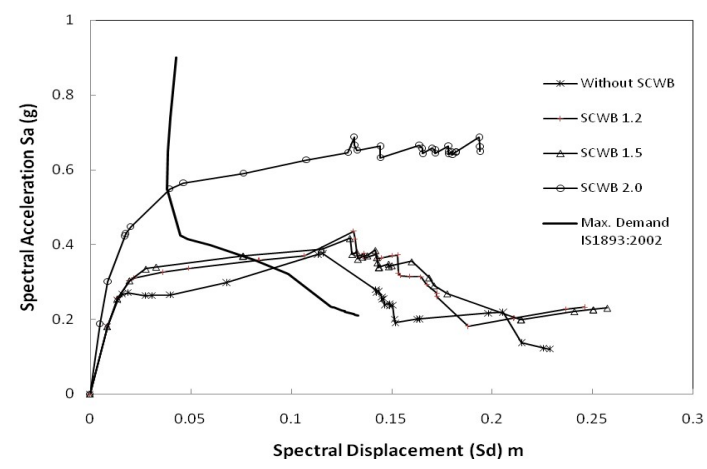

Fig 4 (a) Pushover curve for model 1 with various SCWB factors

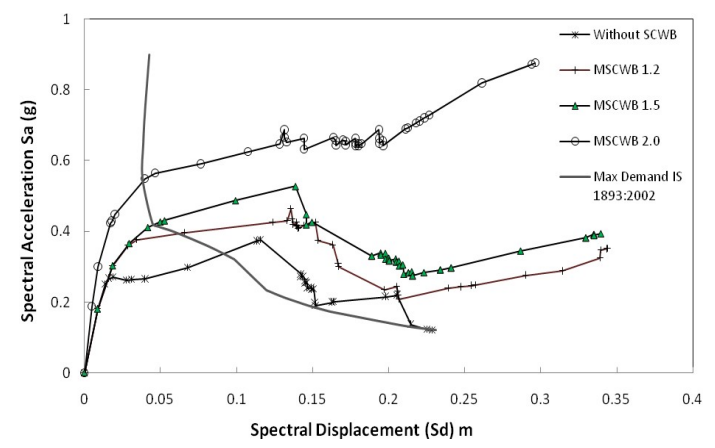

Fig 4 (b) Pushover curve for model 1 with various MSCWB factors

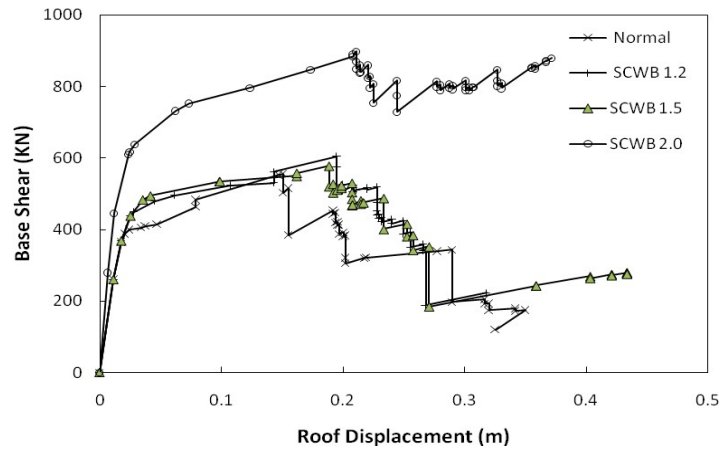

Fig 4 (c) Base shear vs roof displacement curve for model 1 with various SCWB factors

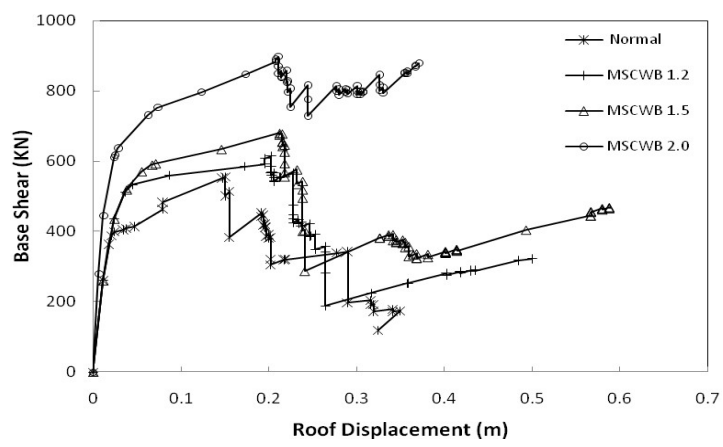

Fig 4 (d) Base shear vs roof displacement curve for model 1 with various MSCWB factors

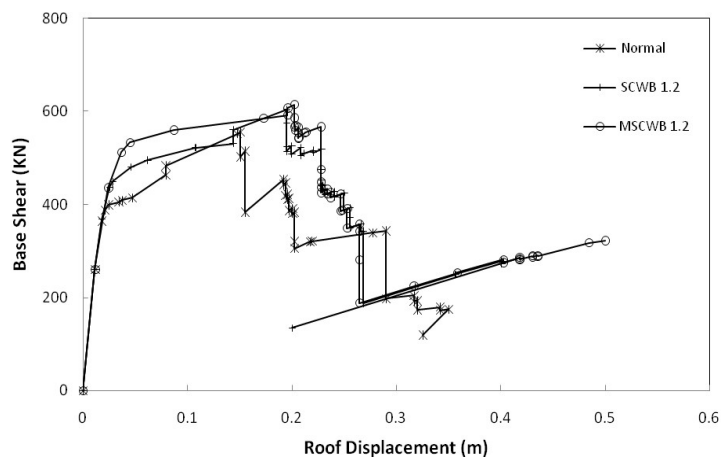

Fig 4 (e) Base shear vs roof displacement curve for model 1 with SCWB / MSCWB factor 1.2

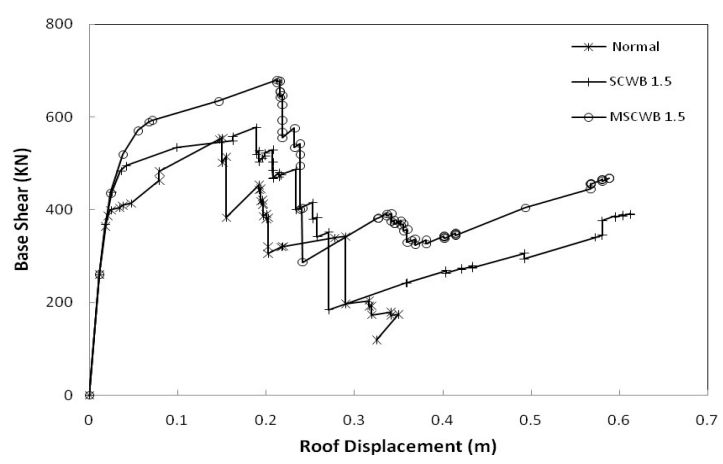

Fig 4 (f) Base shear vs roof displacement curve for model 1 with SCWB and MSCWB factor 1.5 


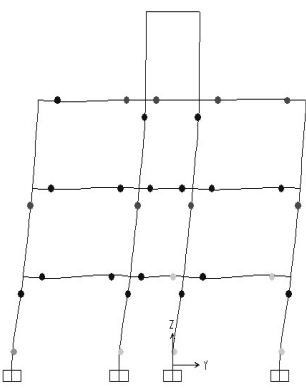

SCWB -1.0

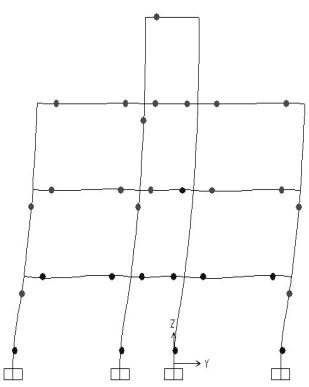

SCWB -1.2

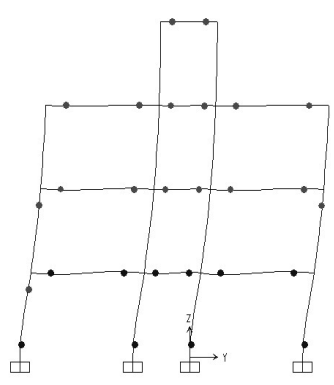

SCWB - 1.5

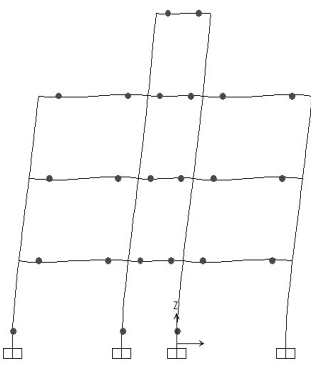

SCWB - 2.0

Fig 5 Hinge formation of model 1 with various SCWB factor at performance point

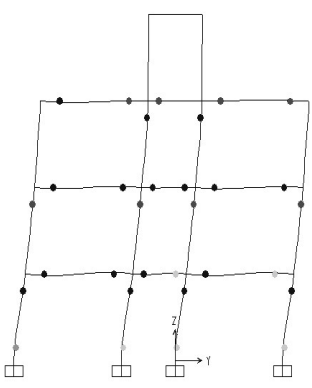

MSCWB - 1.0

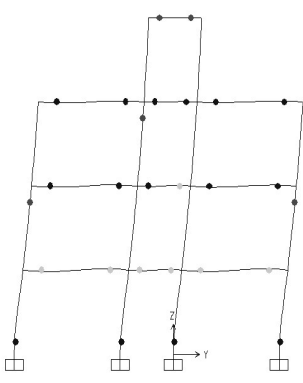

MSCWB - 1.2

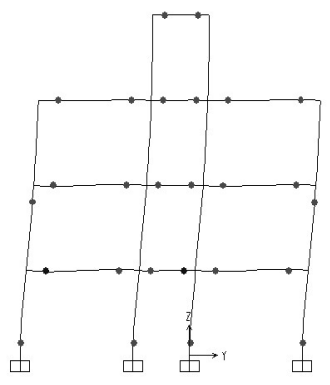

MSCWB - 1.5

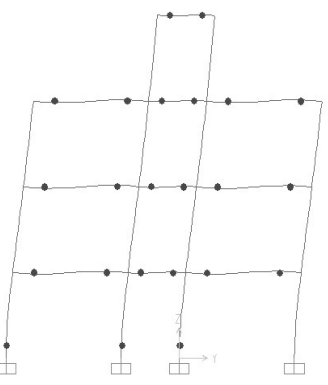

MSCWB - 2.0

Fig 6 Hinge formation of model 1 with various MSCWB factor at performance point

c) Complete elimination of column hinging was not achived even by the higher SCWB factors for all building models. Only SCWB factor of 2.0 (among the chosen values of SCWB factors of 1.0, 1.2, 1.5 and 2.0) prevents all the column hinging except initial level hinge formation at base of bottom storey column (Fig 5 (a) to Fig 5 (d)).

d) All the building models with proposed MSCWB factor show clear enhancement in both failure mechanism as well as capacity curve even with the lower value of MSCWB factor (Fig 4 (b), Fig 4 (d) and Fig 6). Also performance of building model with MSCWB was found better than building model with SCWB factor for all the cases (Fig 4 (e) and Fig 4 (f)).

\section{Conclusion and Recommendation}

The following conclusion has been made based on the results of this study:

a) Failure of present RC structures is initiated with the collapse level hinge formation at the bottom level column. b) There is gradual enhancement in both failure mechanism as well as performance curve with increase in SCWB factor. It can be distinctly observed that the failure mechanism moves from column failure mechanism to beam failure mechanism with increase in SCWB factor.

c) Lower values of SCWB factor (SCWB $\leq$ 1.2) adopted by most of the current codes seems ineffective in the enhancement of performance as well as failure mechanism of structure.

d) As current study is only limited to access the performance of low to medium rise $\mathrm{RC}$ building for limited amount of factors (SCWB $1.0,1.2,1.5,2.0)$, from the current study it can only be concluded that with current SCWB provision very high value of factor $(\mathrm{SCWB}>1.5)$ is required for the complete elimination of column hinging in $\mathrm{RC}$ building at performance point. To determine the optimum value of SCWB factor, the study can be further extended with the narrow variation in factors for low to highrise building as well. 
e) Proposed MSCWB shows better performance over current SCWB factor even for lower value of MSCWB (Performance of MSCWB 1.2 is very similar or better in all the cases than SCWB 1.5) indicating the effective balance between economy as well as performance.

\section{References:}

[1] ACI 318 Committee. (2008). Building Code Requirements for Structural Concrete (ACI 318-08) and Commentary. Farmington Hill, MI, US.

[2] ACI-ASCE. Committee $352 . \quad$ (1985). Recommendations for Design of Beam-Column Joints in Monolithic Reinforced Concrete Structures. American Concrete Institute.

[3] ANSI, A. AISC 341-05 (2005). Seismic Provisions for Structural Steel Buildings. American Institute of Steel Construction. Inc.: Chicago, IL.

[4] Choi, S. W., Kim, Y., Lee, J., Hong, K., \& Park, H. S. (2013). Minimum Column to Beam Strength Ratios for Beam Hinge Mechanisms Based on MultiObjective Seismic Design. Journal of Constructional Steel Research, 88, 53-62.

[5] EN 1998-1 (2004). Eurocode 8: Design of Structures for Earthquake Resistance - Part 1: General Rules, Seismic Actions and Rules for Buildings. The European Union.
[6] IS 1893 (2002). Criteria for Earthquake Resistant Design of Structure, General Provisions and Buildings, Bureau of Indian Standards, New Delhi.

[7] Muljati, I., \& Lumantarna, B. (2008). Performance of Partial Capacity Design on Fully Ductile Moment Resisting Frame in Highly Seismic Area in Indonesia. In The Eleventh East Asia-Pacific Conference on Structural Engineering and Construction (EASEC-11).

[8] Ono, T., Zhao, Y. G., \& Ito, T. (2000). Probabilistic Evaluation of Column Overdesign Factors for Frames. Journal of Structural Engineering, 126(5), 605-611.

[9] Richard, M. J., Albano, L. D., Kelly, D., \& Liel, A. B. (2010). Case Study on the Seismic Performance of Reinforced Concrete Intermediate Moment Frames using ACI Design Provisions. In Structures Congress 2010 (pp. 3523-3534).

[10] Sharfuddin, M., Zhao, Y. G., Idota, H., \& Ansary, M. A. (2010). Probabilistic Evaluation of Column OverDesign Factor for Frame Structures Considering Seismic Base Shear Distribution of BNBC. Journal of Civil Engineering (IEB), 38(2), 109-119.

[11] Yuan, J., \& Hu, D. (2009). Influence of Steel Bars in Monolithic Floor Slabs on the Yielding-Damage Mechanism of Frame Structures. WIT Transactions on the Built Environment, 104, 25-37. 